\title{
Treatment of Pharmaceutical Wastewaters by Hydrogen Peroxide and Zerovalent Iron
}

\author{
Byeong-Cheol Jeon, Se-Yong Nam, Young-Kwon Kim ${ }^{\dagger}$ \\ Department of Civil, Safety \& Environmental Engineering, Hankyong National University, Anseong 456-749, Korea
}

\begin{abstract}
Fenton reaction with zerovalent iron (ZVI) and $\mathrm{Fe}^{2+}$ ions was studied to treat pharmaceutical wastewaters (PhWW) including antibiotics and non-biodegradable organics. Incremental biodegradability was assessed by monitoring biochemical oxygen demand (BOD) changes during Fenton reaction. Original undiluted wastewater samples were used as collected from the pharmaceutical factory. Experiments were carried out to obtain optimal conditions for Fenton reaction under different $\mathrm{H}_{2} \mathrm{O}_{2}$ and ion salts ( $\mathrm{ZVI}$ and Fe ${ }^{2+}$ ) concentrations. The optimal ratio and dosage of $\mathrm{H}_{2} \mathrm{O}_{2} / \mathrm{ZVI}$ were 5 and 25/5 g/L (mass basis), respectively. Also, the optimal ratio and dosage of $\mathrm{H}_{2} \mathrm{O}_{2} / \mathrm{Fe}^{2+}$ ions were 5 and $35 / 7 \mathrm{~g} / \mathrm{L}$ (mass basis), respectively. Under optimized conditions, the chemical oxygen demand (COD) removal efficiency by ZVI was $23 \%$ better than the treatment with $\mathrm{Fe}^{2+}$ ion. The reaction time was $45 \mathrm{~min}$ for ZVI and shorter than $60 \mathrm{~min}$ for $\mathrm{Fe}^{2+}$ ion. The COD and total organic carbon (TOC) were decreased, but BOD was increased under the optimal conditions of $\mathrm{H}_{2} \mathrm{O}_{2} / \mathrm{ZVI}$ $=25 / 5 \mathrm{~g} / \mathrm{L}$, because organic compounds were converted into biodegradable intermediates in the early steps of the reaction. The BOD $/$ TOC ratio was increased, but reverse-wise, the COD/TOC was decreased because of generated intermediates. The biodegradability was increased about 9.8 times (BOD/TOC basis), after treatment with ZVI. The combination of chemical and biological processes seems an interesting combination for treating PhWW.
\end{abstract}

Keywords: Biodegradability, Fenton’s oxidation, Ferrous irons, Pharmaceutical wastewater, Zerovalent iron

\section{Introduction}

The pharmaceutical industry includes manufacturing, fermentation, chemical synthesis, and extraction and formulating processes [1]. The effluents from manufacturing and formulation processes of pharmaceutical products include diverse contaminants of varying aromaticity, including non-biodegradable and structurally complex organic compounds having low biodegradability. Hence, it is not easy to treat those wastewaters by conventional treatment processes. The range of organic compound concentration in pharmaceutical wastewaters (PhWW) is in general 10,000 to $100,000 \mathrm{mg} / \mathrm{L}$ or more on a chemical oxygen demand (COD) basis and lower than $1,000 \mathrm{mg} / \mathrm{L}$ on a biochemical oxygen demand (BOD) basis. PhWW includes antibiotics and other organic molecules that cannot be removed completely by biological processes, since they tend to inhibit the activity of microorganisms. Also, microorganisms have acquired resistance to antibiotics, and these bacteria, when discharged into receiving waters systems, may cause extensive damage to human or ecosystems [2]. In recent studies in North America and Europe, a diverse group of antibiotics have been detected in surface waters and soils and their concentrations are rising to several $\mu \mathrm{g} / \mathrm{L}$ or even higher in some situations [3-5]. In Korea, antibiotics have become of increasing concern, since high concentrations of antibiotics have been found to increase rapidly in surface waters and soils especially near livestock farms [6,7]. The occurrence of antibiotics in surface waters has also been shown to be high enough to contribute to antibiotic resistance [8].

Biological processes, such as activated sludge and membrane bioreactor, have been applied for treatment of PhWW [9, 10]. To reduce the toxicity and enhance their biodegradability, PhWW are often diluted before being subjected to a biological treatment. This certainly increases operation costs, because of the higher wastewater volumes needing to be treated. Therefore, it is necessary to combine the chemical processes with biological processes. PhWW cannot be completely eliminated during biological treatment, because it has a high amount of organics as well as antibiotics. Therefore, a coupling process (biological and chemical process combined) has been used after converting non-biodegradable into biodegradable materials and reducing the toxicity of antibiotics $[1,10]$.

The chemical processes, especially advanced oxidation processes (AOPs), can effectively break down some of the structurally complex organic compounds and bio-inhibitory compounds.

Received April 30, 2013 Accepted October 05, 2013

${ }^{\dagger}$ Corresponding Author

E-mail: ykkim@hknu.ac.kr

Tel: +82-31-670-5173 Fax: +82-31-670-5170 which permits unrestricted non-commercial use, distribution, and repro duction in any medium, provided the original work is properly cited. 
AOPs are one of the favored techniques to remove refractory pollutants involving hydroxyl radicals, a powerful oxidant. The combinations $\mathrm{O}_{3} / \mathrm{UV}, \mathrm{O}_{3} / \mathrm{H}_{2} \mathrm{O}_{2}, \mathrm{H}_{2} \mathrm{O}_{2} / \mathrm{UV}$, and $\mathrm{TiO}_{2} / \mathrm{UV}$ are techniques using oxidants like ozone and UV. Their application is nevertheless somewhat restricted depending on the characteristics of the wastewaters, such as $\mathrm{pH}$, total dissolved solids, turbidity, and gas solubility.

During Fenton reaction, $\mathrm{Fe}^{2+}$ catalyzes the decomposition of $\mathrm{H}_{2} \mathrm{O}_{2}$ into hydroxyl radicals, which are then able to convert organic pollutants into more easily biodegradable compounds, such as lower molecular weight fatty acids. Further microbial degradation can then transform these fatty acids into $\mathrm{CO}_{2}$ and $\mathrm{H}_{2} \mathrm{O}$. Unfortunately, this process generates a large amount of sludge, because Fenton reaction relies on the supply of $\mathrm{Fe}^{2+}$ ions and $\mathrm{H}_{2} \mathrm{O}_{2} \cdot \mathrm{Fe}^{2+}$ ions are oxidized to $\mathrm{Fe}^{3+}$ ions and oxidized $\mathrm{Fe}^{3+}$ ions precipitate as hydroxides at neutral or alkaline $\mathrm{pH}$. To prevent the precipitation of Fe hydroxide, the $\mathrm{pH}$ should be kept acidic ( $\mathrm{pH} 2-5)$. Also, untreated iron salts may harm receiving water systems, because iron salts consume oxygen. To overcome the drawback in Fenton reaction, an alternate approach is proposed that reduces the generation of sludge and operating costs. This new approach uses zerovalent iron ( $\mathrm{ZVI}, \mathrm{Fe}^{0}$ ) as the catalyst in Fenton process instead of $\mathrm{Fe}^{2+}$. The oxidized $\mathrm{Fe}^{3+}$ ions form hydroxyl complexes at high $\mathrm{pH}$, and those complexes do not redissolve readily and do not participate in the reduction steps of the classic Fenton reaction [11]. The oxidation of ZVI at acidic conditions involves producing $\mathrm{Fe}^{2+}$, which promote the generation of hydroxyl radicals (Eqs. (1) and (2)). A fast recycling of $\mathrm{Fe}^{3+}$ into $\mathrm{Fe}^{2+}$ species at the metal surface can occur following (Eq. (3)). Moreover, ZVI has been used for the degradation of different model pollutants. ZVI oxidation by dissolved oxygen produces $\mathrm{H}_{2} \mathrm{O}_{2}$ via a two-electron transfer from the metal surface to oxygen (Eq. (4)). The $\mathrm{H}_{2} \mathrm{O}_{2}$ generated is reduced to water (Eq. (5)) as well as converted to $\mathrm{HO}$ or $\mathrm{Fe}(\mathrm{IV})$ by reaction with $\mathrm{Fe}^{2+}$ (Eqs. (1) and (6), respectively) $[12,13]$.

$$
\begin{aligned}
& \mathrm{Fe}^{2+}+\mathrm{H}_{2} \mathrm{O}_{2} \rightarrow \mathrm{Fe}^{3+}+\mathrm{HO}+\mathrm{HO}^{-} \\
& \mathrm{Fe}^{0}+2 \mathrm{H}^{+} \rightarrow 2 \mathrm{Fe}^{2+}+\mathrm{H}_{2} \\
& 2 \mathrm{Fe}^{3+}+\mathrm{Fe}^{0} \rightarrow 3 \mathrm{Fe}^{2+} \\
& \mathrm{Fe}^{0}+\mathrm{O}_{2}+2 \mathrm{H}^{+} \rightarrow \mathrm{Fe}^{2+}+\mathrm{H}_{2} \mathrm{O}_{2} \\
& \mathrm{Fe}^{0}+\mathrm{H}_{2} \mathrm{O}_{2}+2 \mathrm{H}^{+} \rightarrow \mathrm{Fe}^{2+}+2 \mathrm{H}_{2} \mathrm{O} \\
& \mathrm{Fe}^{2+}+\mathrm{H}_{2} \mathrm{O}_{2} \rightarrow \mathrm{FeO}^{2+}+\mathrm{H}_{2} \mathrm{O}
\end{aligned}
$$

Table 1. Characteristics of samples and operating conditions in extended aeration

\begin{tabular}{lc}
\hline \multicolumn{2}{l}{ Samples (average value) } \\
\hline $\mathrm{pH}$ & 6.8 \\
$\mathrm{BOD}_{5}(\mathrm{mg} / \mathrm{L})$ & 1.780 \\
TOC $(\mathrm{mg} / \mathrm{L})$ & 8,750 \\
$\mathrm{COD}_{\mathrm{Cr}}(\mathrm{mg} / \mathrm{L})$ & 15,000 \\
\hline Operating conditions in extended aeration & 0.04 \\
\hline F/M ratio $(\mathrm{kg}$ BOD $/ \mathrm{kg}$ MLVSS) & 4,500 \\
MLSS $(\mathrm{mg} / \mathrm{L})$ & 25 \\
SRT (day) & 0.2 \\
BOD loading rate $\left(\mathrm{kg} / \mathrm{m}^{3} /\right.$ day $)$ &
\end{tabular}

BOD: biochemical oxygen demand, TOC: total organic carbon, COD: chemical oxygen demand, F/M: food-to-microorganism ratio, MLVSS: mixed liquor volatile suspended solids, MLSS: mixed liquor suspended solids, SRT: solids retention time.
The antibiotics being synthesized and manufactured in Korea are known $\beta$-lactam antibiotics, and they account for $50 \%$ or more of production [14]. Cephradine is a major representative of $\beta$-lactam antibiotics and is usually used to treat inflammations, such as respiratory infection, urinary tract infection, abscess, and ear infection, etc. This investigation was aimed at studying the operating conditions and improvement of its biodegradability by Fenton reaction with ZVI. The efficiency was also compared to Fenton reaction with $\mathrm{Fe}^{2+}$ ions. The target was the wastewater of a cephradine manufacturing site. The experiments were carried out under different parameters $\left(\mathrm{H}_{2} \mathrm{O}_{2} / \mathrm{ZVI}\right.$ and $\mathrm{Fe}^{2+}$ ion ratios, and reaction time). The improvement of biodegradability was optimized through variations of ratios of BOD/TOC and COD/TOC, and various combinations of chemical and biological process were tested to improve biodegradability $[15,16]$.

\section{Materials and Methods}

\subsection{Pharmaceutical Wastewater Samples}

Samples were collected at 'A Pharmaceutical Co., Ltd.' in Gyeonggido, Korea. This factory produces mainly cephradine products from chemical synthesis and formulation processes. The daily generation of wastewater is $250 \mathrm{~m}^{3} /$ day from the formulation process and the washing of the equipment. The treatment system uses an extended aeration process and samples were collected from the treatment facility upstream from the water treatment, i.e., raw wastewaters were used for this study. Samples were pretreated to remove solids, by filtration through a 0.45- $\mathrm{um}$ membrane filter (mixed-cellulose ester, ø $47 \mathrm{~mm}$; product \#1353001; HACH, Loveland, CO, USA). All samples were kept cold $\left(4^{\circ} \mathrm{C} \pm 0.2^{\circ} \mathrm{C}\right)$ to prevent substrate decomposition. The sample characteristics and the operation conditions of the extended aeration are given in Table 1.

\subsection{Experimental Procedure}

Experiments were carried out to determine the optimum ratio of $\mathrm{H}_{2} \mathrm{O}_{2} / \mathrm{ZVI}$ and $\mathrm{H}_{2} \mathrm{O}_{2} / \mathrm{Fe}^{2+}$ ions. The tests were conducted using a $1,000 \mathrm{~mL}$ sample of undiluted wastewaters (initial COD $=15,000 \mathrm{mg} / \mathrm{L}$ ) in glass jars with magnetic stirrers. The samples were acidified to $\mathrm{pH} 3$ and Fenton reagent was added into the jars. The ratios of $\mathrm{H}_{2} \mathrm{O}_{2} / \mathrm{Fe}^{2+}$ in Fenton reagent were 1, 3, 5, and 7 as mass ratio, while $\mathrm{Fe}^{2+}$ ions concentration was kept constant at 5 $\mathrm{g} / \mathrm{L}$. After determination of the optimum ratio, other parameters were changed. The jars were covered with Parafilm (Whatman, Maidstone, Kent, UK) to prevent evaporation of volatile compounds. The reaction times were $0,15,30,45,60$, and $120 \mathrm{~min}$. The samples were acidified to $\mathrm{pH} 3$, because Fenton reaction is most effective at low $\mathrm{pH}$, and acidic conditions also prevent the auto-decomposition of $\mathrm{H}_{2} \mathrm{O}_{2}[11,17]$. At planned reactions times, the stirring equipment was removed and the $\mathrm{pH}$ was raised to 8 to allow settling down of the generated solids for $30 \mathrm{~min}$. The supernatants were then filtered by passing through a $0.45-\mu \mathrm{m}$ membrane filter (mixed-cellulose ester, $ø 47 \mathrm{~mm}$; $\mathrm{HACH}$ ), and the filtrates were measured for $\mathrm{BOD}_{5}, \mathrm{COD}$, and TOC. The ZVI experiments followed the same experimental procedures as for $\mathrm{Fe}^{2+}$ ions. ZVI powder was added into the samples and stirred for 5 min in order to be distributed among ZVI and samples completely. The $\mathrm{H}_{2} \mathrm{O}_{2}$ was added into the jars according to the different $\mathrm{H}_{2} \mathrm{O}_{2}$ /ZVI ratios. 
Acid and base adjustments were made using $0.1 \mathrm{M} \mathrm{H}_{2} \mathrm{SO}_{4}$ and 0.1 $\mathrm{M} \mathrm{NaOH}$. The $\mathrm{Fe}^{0}$ (325 mesh iron powder, $97 \%$ ), $\mathrm{Fe}^{2+}$ ions (99\% $\mathrm{FeSO}_{4} \cdot 7 \mathrm{H}_{2} \mathrm{O}$ ), and $\mathrm{H}_{2} \mathrm{O}_{2}$ (35 wt $\%$ solution) were the American Chemical Society (ACS) or reagent grade from Sigma-Aldrich. COD was determined by the colorimetric method (COD photometer, $610 \mathrm{~nm}$; K-7360S; CHEMetrics Inc., Midland, VA, USA), and TOC was analyzed using a TOC analyzer (TOC-5000A; Shimadzu, Kyoto, Japan). BOD $_{5}$ was measured using a BOD meter (PCD-6500; Sechang Instrument, Seoul, Korea). All analytical methods used standard methods [18]. COD was analyzed to determine the optimal condition for Fenton oxidation in terms of $\mathrm{H}_{2} \mathrm{O}_{2} / \mathrm{ZVI}$ and $\mathrm{H}_{2} \mathrm{O}_{2} / \mathrm{Fe}^{2+}$ ratios (mass basis). The values of BOD/ TOC and COD/TOC were used to estimate the improvement of biodegradability.

\section{Results and Discussion}

\subsection{Determination of the $\mathrm{H}_{2} \mathrm{O}_{2} /\left(\mathrm{ZVI}\right.$ or $\left.\mathrm{Fe}^{2+}\right)$ Ratio}

Experiments were conducted to determine the optimal ratio of $\mathrm{H}_{2} \mathrm{O}_{2}$ /iron salts at various dosages of $\mathrm{H}_{2} \mathrm{O}_{2}$, while maintaining the dosage of iron salts (ZVI or $\mathrm{Fe}^{2+}$ ) at $5 \mathrm{~g} / \mathrm{L}$. When the $\mathrm{H}_{2} \mathrm{O}_{2} / \mathrm{Fe}^{2+}$ ratio was increased from 1 to 5 , the COD removal efficiency was increased from $58.7 \%$ to $74.3 \%$ for a reaction time of $120 \mathrm{~min}$ in Fig. 1(a). But COD removal efficiencies were not improved by the increase of $\mathrm{H}_{2} \mathrm{O}_{2} / \mathrm{Fe}^{2+}$ ratio up to 7 . It is probable that excess $\mathrm{H}_{2} \mathrm{O}_{2}$ becomes oxygen and water by auto-decomposition, or acts as a scavenger, and thus consumes hydroxyl radicals [19-21]. Using ZVI, the maximum COD removal value was again observed using a ratio of 5 giving $91.4 \%$ removal efficiency in 120 min reaction. The phenomenon of hydroxyl scavenging by excess $\mathrm{H}_{2} \mathrm{O}_{2}$ was also observed with a lower efficiency for higher oxidant ratio. COD removal efficiency was higher for Fenton reaction using ZVI than $\mathrm{Fe}^{2+}$ ion with the measured COD removal efficiency improved by roughly $23 \%$ through ZVI.

Tests were carried out to elucidate the optimum dosage of Fenton reagents. The iron salts were increased from 1 to $9 \mathrm{~g} / \mathrm{L}$ and $\mathrm{H}_{2} \mathrm{O}_{2}$ dosages were maintained proportional to the iron salt doses. During this test, the ratio of $\mathrm{H}_{2} \mathrm{O}_{2}$ /iron salts was always kept at 5 (Fig. 2). When the $\mathrm{H}_{2} \mathrm{O}_{2} / \mathrm{Fe}^{2+}$ ratios were increased from $5 / 1$ to $45 / 9 \mathrm{~g} / \mathrm{L}$ (as mass ratio), the COD removal efficiencies were increased from $38.2 \%$ to $88.3 \%$. However, its increments were insignificant between an $\mathrm{H}_{2} \mathrm{O}_{2} / \mathrm{Fe}^{2+}$ ratio range of $35 / 7$ and $45 / 9 \mathrm{~g} / \mathrm{L}$. Therefore, the optimal dosage of Fenton reagent by $\mathrm{Fe}^{2+}$ ions was determined to be $\mathrm{H}_{2} \mathrm{O}_{2} / \mathrm{Fe}^{2+}=35 / 7 \mathrm{~g} / \mathrm{L}$.

In Fenton reaction with ZVI, COD removal efficiencies were rapidly increased from $43.7 \%$ to $91.4 \%$, when the ratios of $\mathrm{H}_{2} \mathrm{O}_{2}$ / ZVI were changed from $5 / 1$ to $25 / 5 \mathrm{~g} / \mathrm{L}$. But further increases from $25 / 5$ to $45 / 9 \mathrm{~g} / \mathrm{L}$ did not show any significant improvements. The optimal dosage of Fenton reagents is a ratio of $\mathrm{H}_{2} \mathrm{O}_{2}$ / $\mathrm{ZVI}=25 / 5 \mathrm{~g} / \mathrm{L}$. If ZVI was used to treat the PhWW, a lower mass of reagents is required, relative to $\mathrm{Fe}^{2+}$ ions.

\subsection{Comparison with the Effectiveness between $\mathrm{Fe}^{2+}$ and ZVI in Fenton Reaction}

Experiments were carried out to compare the effectiveness of $\mathrm{ZVI}$ and $\mathrm{Fe}^{2+}$ ions in Fenton reaction. After reaction for $120 \mathrm{~min}$, the remaining concentrations of COD were measured at each ratio of $\mathrm{H}_{2} \mathrm{O}_{2}$ /iron salts, and the fractions of $\mathrm{COD}_{\mathrm{ZVI}} / \mathrm{COD}_{\mathrm{Fe}(\mathrm{II})}$ were compared. As shown in Fig. 3, all of the $\mathrm{COD}_{\mathrm{ZVI}} / \mathrm{COD}_{\mathrm{Fe}(\mathrm{II})}$ fraction
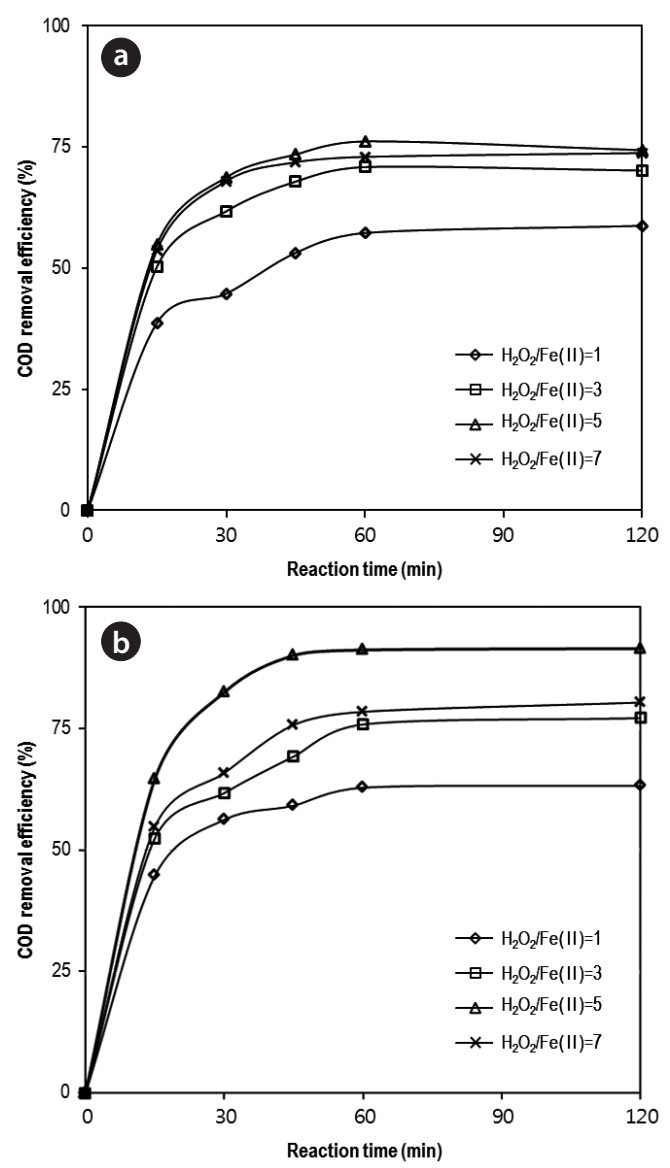

Fig. 1. Determination of optimum $\mathrm{H}_{2} \mathrm{O}_{2}$ /iron salts ratio at various $\mathrm{H}_{2} \mathrm{O}_{2}$ dosages $(\mathrm{pH}=3$; initial COD $=15,000 \mathrm{mg} / \mathrm{L}$ ). (a) $\mathrm{Fe}(\mathrm{II})=5$ $\mathrm{g} / \mathrm{L}$, (b) ZVI $[\mathrm{Fe}(0)]=5 \mathrm{~g} / \mathrm{L}$. COD: chemical oxygen demand, ZVI: zerovalent iron.

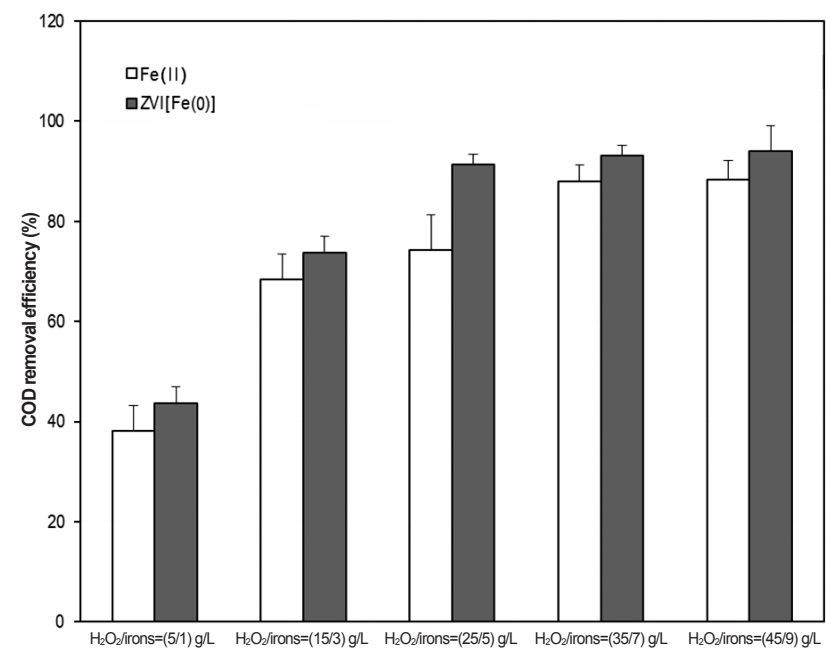

Fig. 2. Effect of dosages with iron salts and $\mathrm{H}_{2} \mathrm{O}_{2}$ on COD removal efficiencies ( $\mathrm{pH}=3$; initial COD $=15,000 \mathrm{mg} / \mathrm{L}$; dosage of iron salts $=1,3,5$, and $7 \mathrm{~g} / \mathrm{L}$ ). The error bars represent the standard errors of duplicated experiments. COD: chemical oxygen demand, ZVI: zerovalent iron. 


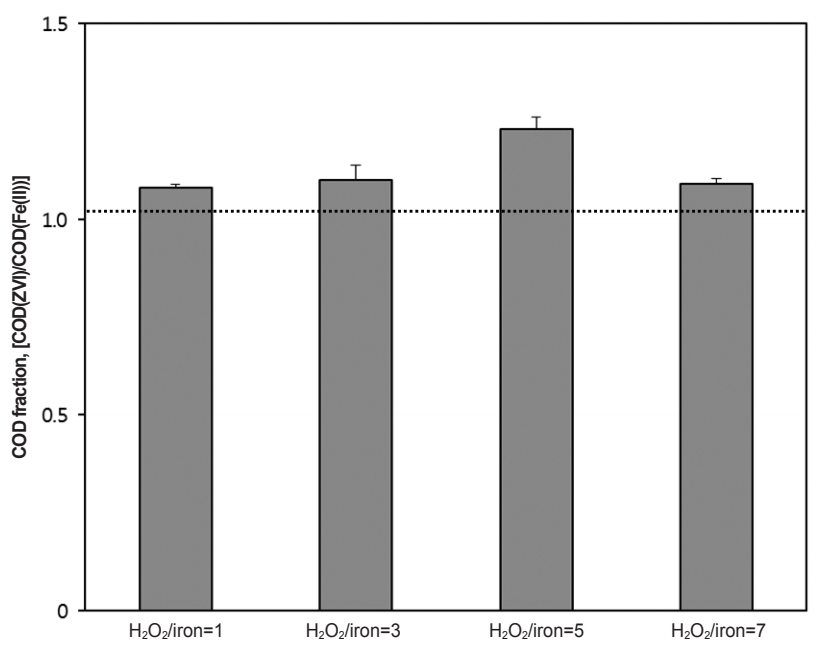

Fig. 3. Estimation of the effectiveness between ZVI and $\mathrm{Fe}^{2+}$ ion for different $\mathrm{H}_{2} \mathrm{O}_{2}$ /iron salts ratios $(\mathrm{pH}=3$; initial COD $=15,000 \mathrm{mg} / \mathrm{L}$; iron salts $=5 \mathrm{~g} / \mathrm{L}$; reaction time $=120 \mathrm{~min}$ ). The error bars represent the standard errors of duplicated experiments. COD: chemical oxygen demand, ZVI: zerovalent iron.

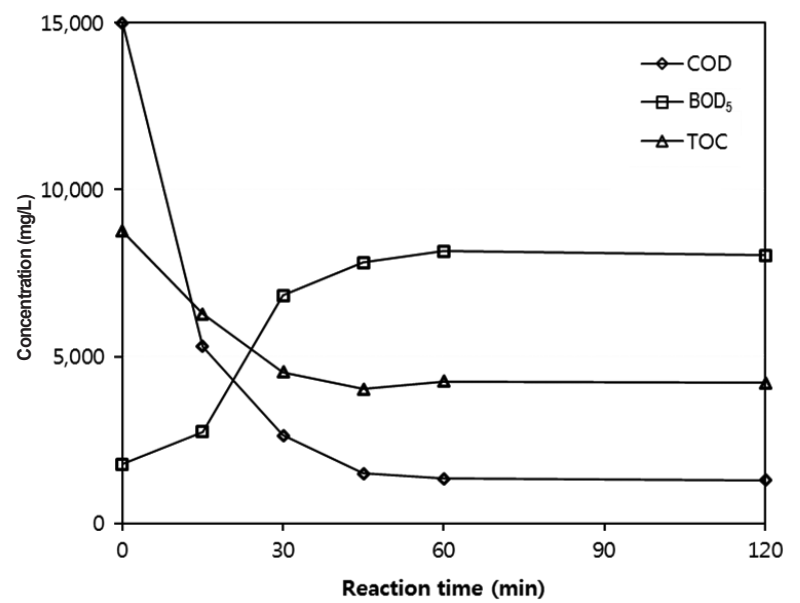

Fig. 4. Changes of $\mathrm{BOD}_{5}, \mathrm{COD}$, and TOC concentrations during Fenton reaction with ZVI ( $\mathrm{pH}=3$; initial COD = 15,000 mg/L; $\mathrm{H}_{2} \mathrm{O}_{2} /$ $\mathrm{ZVI}=25 / 5 \mathrm{~g} / \mathrm{L}$ mass basis). BOD: biochemical oxygen demand, COD: chemical oxygen demand, TOC: total organic carbon, ZVI: zerovalent iron.

Table 2. Pearson correlation coefficients between the COD, BOD, and TOC values

\begin{tabular}{lccc}
\hline & COD & BOD $_{5}$ & TOC \\
\hline COD & 1 & - & - \\
BOD $_{5}$ & $-0.875^{\mathrm{a}}$ & 1 & - \\
TOC & $0.983^{\mathrm{b}}$ & -0.941 & 1 \\
\hline
\end{tabular}

COD: chemical oxygen demand, BOD: biochemical oxygen demand, TOC: total organic carbon.

${ }^{a}$ Negative or inverse association, ${ }^{\mathrm{b}}$ positive association.

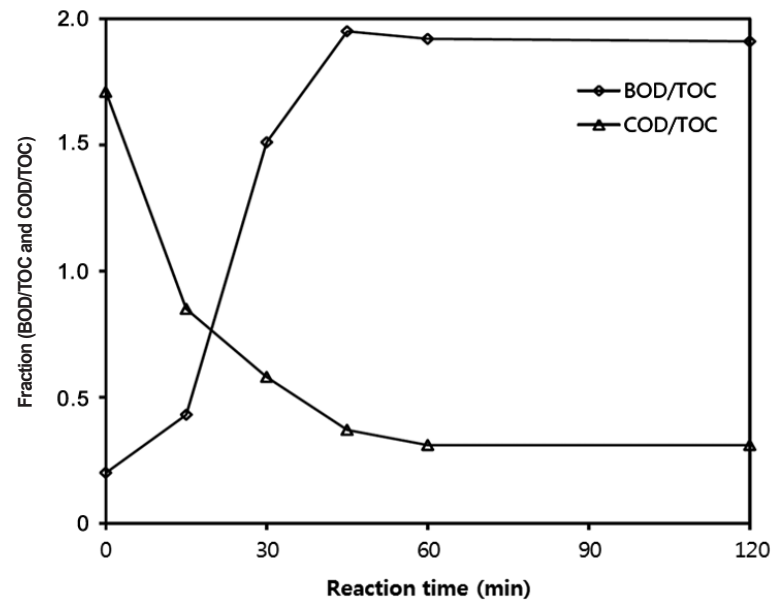

Fig. 5. Change of fraction between $\mathrm{BOD} / \mathrm{TOC}$ and $\mathrm{COD} / \mathrm{TOC}$ during Fenton reaction with ZVI $\left(\mathrm{pH}=3\right.$; initial COD $=15,000 \mathrm{mg} / \mathrm{L} ; \mathrm{H}_{2} \mathrm{O}_{2} /$ $\mathrm{ZVI}=25 / 5 \mathrm{~g} / \mathrm{L}$ mass basis). BOD: biochemical oxygen demand, COD: chemical oxygen demand, TOC: total organic carbon, ZVI: zerovalent iron.

values were higher than 1 within the range of different $\mathrm{H}_{2} \mathrm{O}_{2}$ /iron salt ratios. Again, this emphasizes that ZVI is more efficient than $\mathrm{Fe}^{2+}$ ions to treat $\mathrm{PhWW}$ through Fenton reaction. The maximum fraction value was 1.23 at an $\mathrm{H}_{2} \mathrm{O}_{2}$ /iron salts $=5$ ratio, and the resulting COD removal efficiency by ZVI was 1.23 times higher than using $\mathrm{Fe}^{2+}$. This increased efficiency is attributed to the ability of ZVI, not only to convert $\mathrm{Fe}^{3+}$ ions into $\mathrm{Fe}^{2+}$ ions (see Eq. (4)), but regenerated $\mathrm{Fe}^{2+}$ ions can also further participate in the activated reaction of $\mathrm{H}_{2} \mathrm{O}_{2}[12,13]$.

\subsection{Assessment of Biodegradability by BOD/TOC and COD/TOC Ratio}

Fig. 4 shows the changes of BOD, COD, and TOC at $\mathrm{H}_{2} \mathrm{O}_{2} / \mathrm{ZVI}$ $=25 / 5 \mathrm{~g} / \mathrm{L}$. The COD values were steeply decreased during the early stages of the reaction, but the BOD values were increased. The TOC values also steadily decreased. The rapid reduction of COD was caused by the elimination of organic carbon and the slow reduction of TOC was the result of converting a part of the organic molecules into intermediates. BOD was increased through the formation of biodegradable low molecular weight fatty acids intermediates in the early stages of reaction. The incremental increase of BOD seemed to stop after a reaction of 45 min, presumably because the intermediates were being oxidized to carbon dioxide and water at the latter stages of reaction.

The enhancement of biodegradability was in general observed for the $\mathrm{BOD} / \mathrm{TOC}, \mathrm{BOD} / \mathrm{COD}$, and $\mathrm{COD} / \mathrm{TOC}$ ratios. Table 2 shows the degree of association between two variables of BOD, COD, and TOC by Pearson correlation. The correlation coefficients of BOD/COD, BOD/TOC, and COD/TOC were -0.875 , -0.941 , and 0.983 , respectively. Because the coefficients for BOD/ TOC and COD/TOC are higher, they seem better predictors of biodegradability. Khan et al. [22] observed that the BOD/COD ratio had restrictions, such as low sensitivity against low organics or non-biodegradable wastewater. Fig. 5 shows that the BOD/ 
TOC values were increased 0.2 to 1.95 during the first $45 \mathrm{~min}$, because the BOD was increased about $77 \%$ but the TOC decreased about $54 \%$. It is suggested that organic compounds were effectively decomposed into intermediates by Fenton with ZVI. The increments of BOD/TOC were slightly decreased from 1.95 to 1.91 after $45 \mathrm{~min}$, because the BOD values only increased $3 \%$ in the latter stages of the reaction. The COD/TOC ratio decreased to 0.37 during the first $45 \mathrm{~min}$ and it was stable afterwards. This suggests that the formation of intermediates progressed rapidly for the initial $45 \mathrm{~min}$ period. It has been previously reported that the diminution of the COD/TOC ratio is linked to the generation of intermediates [23-25]. It seemed probable that the biodegradability increased about 9.8 times according to the BOD/TOC ratio after treatment using ZVI. Increasing the biodegradability through Fenton reaction with ZVI seems an opportune possibility to combine chemical and biological processes for PhWW.

\section{Conclusions}

This paper explains the treatability of PhWW and the enhancement of biodegradability by Fenton reaction with ZVI. The following results can be drawn. 1) In the experiment to determine the optimal ratio of $\mathrm{H}_{2} \mathrm{O}_{2}$ /iron salts, the maximum COD removal value between $\mathrm{ZVI}$ and $\mathrm{Fe}^{2+}$ ion was observed using a ratio of 5, giving $91.4 \%$ and $76.1 \%$ removal efficiency in $120 \mathrm{~min}$ reaction, respectively. The COD removal efficiency was improved by $23 \%$ using ZVI instead of $\mathrm{Fe}^{2+}$. 2) The optimum dosages of ZVI and $\mathrm{Fe}^{2+}$ ion were 25/5 and 35/7 g/L (mass basis), respectively, and the COD removal efficiencies were $91.4 \%$ (at ZVI) and $88.3 \%$ (at $\mathrm{Fe}^{2+}$ ion). If $\mathrm{ZVI}$ was used to treat the PhWW, it used less reagents than the use of $\mathrm{Fe}^{2+}$ ions. This means that it is more efficient to use ZVI than $\mathrm{Fe}^{2+}$ ions, as it reduces the operating costs and improves the treatment efficiency. 3) A comparison of the effectiveness between $\mathrm{ZVI}$ and $\mathrm{Fe}^{2+}$ ions was used for the fractions of $\mathrm{COD}_{\mathrm{ZVI}} / \mathrm{COD}_{\mathrm{Fe}(\mathrm{III}}$. The $\mathrm{COD}_{\mathrm{ZVI}} / \mathrm{COD}_{\mathrm{Fe}(\mathrm{II})}$ fraction values were higher than 1 within the whole ratios of $\mathrm{H}_{2} \mathrm{O}_{2}$ /iron salts. It was shown that ZVI was more efficient than $\mathrm{Fe}^{2+}$ ions in treating PhWW by Fenton reaction. The COD removal efficiency by ZVI was enhanced 1.23 times over the use of $\mathrm{Fe}^{2+}$ ions. 4) $\mathrm{In}_{2} \mathrm{O}_{2}$ / $\mathrm{ZVI}=25 / 5 \mathrm{~g} / \mathrm{L}$, the COD and TOC values decreased, but the BOD increased, because organic molecules were converted into biodegradable intermediates. The BOD/TOC values increased, but in contrast, the COD/TOC ratios decreased in the early steps of the reaction, because of generated intermediates. The biodegradability was enhanced about 9.8 times (BOD/TOC basis) after treatment using ZVI.

\section{Acknowledgments}

This work was supported by a research grant from Hankyong National University for an academic exchange program in 2011.

\section{References}

1. US Environmental Protection Agency. Guides to pollution prevention: the pharmaceutical industry. Cincinnati: US Environmental Protection Agency; 1991.

2. Halling-Sorensen B, Nors Nielsen S, Lanzky PF, Ingerslev F, Holten Lutzhoft HC, Jorgensen SE. Occurrence, fate and ef- fects of pharmaceutical substances in the environment: a review. Chemosphere 1998;36:357-393.

3. Pei R, Kim SC, Carlson KH, Pruden A. Effect of river landscape on the sediment concentrations of antibiotics and corresponding antibiotic resistance genes (ARG). Water Res. 2006;40:2427-2435.

4. Martinez-Carballo E, Gonzalez-Barreiro C, Scharf S, Gans O. Environmental monitoring study of selected veterinary antibiotics in animal manure and soils in Austria. Environ. Pollut. 2007;148:570-579.

5. Pailler JY, Krein A, Pfister L, Hoffmann L, Guignard C. Solid phase extraction coupled to liquid chromatography-tandem mass spectrometry analysis of sulfonamides, tetracyclines, analgesics and hormones in surface water and wastewater in Luxembourg. Sci. Total Environ. 2009;407:4736-4743.

6. Oh HK, Park JH. Characteristics of antibiotic resistant bacteria in urban sewage and river. J. of Korean Soc. Environ. Eng. 2009;31:232-239.

7. Lee SS, Kim SC, Kim KR, Kwon OK, Yang JE, Ok YS. Seasonal monitoring of residual veterinary antibiotics in agricultural soil, surface water and sediment adjacent to a poultry manure composting facility. Korean J. Environ. Agric. 2010; 29:273-281.

8. Segura PA, Francois M, Gagnon C, Sauve S. Review of the occurrence of anti-infectives in contaminated wastewaters and natural and drinking waters. Environ. Health Perspect. 2009;117:675-684.

9. Karthikeyan KG, Meyer MT. Occurrence of antibiotics in wastewater treatment facilities in Wisconsin, USA. Sci. Total Environ. 2006;361:196-207.

10. Zhou P, Su C, Li B, Qian Y. Treatment of high-strength pharmaceutical wastewater and removal of antibiotics in anaerobic and aerobic biological treatment processes. J. Environ. Eng. 2006;132:129-136.

11. Lipczynska-Kochany E, Kochany J. Effect of humic substances on the Fenton treatment of wastewater at acidic and neutral pH. Chemosphere 2008;73:745-750.

12. Namkung KC, Burgess AE, Bremner DH. A Fenton-like oxidation process using corrosion of iron metal sheet surfaces in the presence of hydrogen peroxide: a batch process study using model pollutants. Environ. Technol. 2005;26:341-352.

13. Bremner DH, Burgess AE, Houllemare D, Namkung KC. Phenol degradation using hydroxyl radicals generated from zero-valent iron and hydrogen peroxide. Appl. Catal. B Environ. 2006;63:15-19.

14. Kim YK. Treatment of pharmaceutical wastewater by subcritical and supercritical water oxidation. J. of Korean Soc. Environ. Eng. 2003;25:1305-1310.

15. Adams CD, Scanlan PA, Secrist ND. Oxidation and biodegradability enhancement of 1,4-dioxane using hydrogen peroxide and ozone. Environ. Sci. Technol. 1994;28:1812-1818.

16. Mater L, Rosa EV, Berto J, Correa AX, Schwingel PR, Radetski CM. A simple methodology to evaluate influence of $\mathrm{H}_{2} \mathrm{O}_{2}$ and $\mathrm{Fe}(2+)$ concentrations on the mineralization and biodegradability of organic compounds in water and soil contaminated with crude petroleum. J. Hazard. Mater. 2007;149:379-386.

17. Monahan MJ, Teel AL, Watts RJ. Displacement of five metals sorbed on kaolinite during treatment with modified Fenton's reagent. Water Res. 2005;39:2955-2963.

18. Eaton AD, Clesceri LS, Rice EW, Greenberg AR. Standard methods for the examination of water and wastewater. 21st ed. Washington: American Public Health Association; 2005. 
19. Yu S, Lee B, Lee M, Cho IH, Chang SW. Decomposition and mineralization of cefaclor by ionizing radiation: kinetics and effects of the radical scavengers. Chemosphere 2008;71:21062112.

20. Dincer AR, Karakaya N, Gunes E, Gunes Y. Removal of COD from oil recovery industry wastewater by the advanced oxidation processes (AOP) based on $\mathrm{H}_{2} \mathrm{O}_{2}$. Glob. NESTJ. 2008;10: 31-38.

21. Cortez S, Teixeira P, Oliveira R, Mota M. Fenton's oxidation as post-treatment of a mature municipal landfill leachate. World Acad. Sci. Eng. Technol. 2009;57:87-90.

22. Khan E, Wirojanagud W, Sermsai N. Effects of iron type in Fenton reaction on mineralization and biodegradability enhancement of hazardous organic compounds. J. Hazard. Mater. 2009;161:1024-1034.

23. Marco A, Esplugas S, Saum G. How and why combine chemical and biological processes for wastewater treatment. Water Sci.Technol. 1997;35:321-327.

24. Gilbert E. Biodegradability of ozonation products as a function of COD and DOC elimination by example of substituted aromatic substances. Water Res. 1987;21:1273-1278

25. Imai A, Onuma K, InamoriY, Sudo R. Effects of pre-ozonation in refractory leachate treatment by the biological activated carbon fluidized bed process. Environ. Technol. 1998;19:213221. 